\title{
THE INTRAFAMILIAL TRANSMISSION OF RHEUMATOID ARTHRITIS-VIII
}

\author{
SUMMARY OF FINDINGS \\ Sidney Cobb, M.D., William J. Schull, Ph.D., Ernest Harburg, Ph.D. and \\ Stanislav V. Kasl, Ph.D. \\ Survey Research Centre, Institute for Social Research, The University of Michigan, Ann Arbor, \\ Michigan
}

(Received 26 August 1968)

A SAMPLING of 49 family clusters consisting of a key person with arthritis, his (her) spouse, a sibling and the sibling's spouse, 2 cousins, and an unrelated individual were interviewed three times with regard to their arthritis and a variety of social and psychological factors. The sample was drawn in part from a national random sample and in part from an arthritis clinic.

A detailed interview measure was developed in order to classify respondents with regard to rheumatoid arthritis. It is estimated that this Rheumatoid Arthritis (RA) Measure has a sensitivity of 86 per cent and a specificity of 98 per cent. Altogether 324 respondents, 169 men and 155 women, are involved in this study. Of these, 66 are classified as having RA: 49 women and 17 men. Of the 49 key persons, 43 were eventually classified as having RA; the additional 23 RA's were other members of the family clusters.

The results of this study do not support the conclusion that heredity is an important feature of the etiology of rheumatoid arthritis. However, a number of social-pshycological factors were revealed as contributing to the disease. These results are summarized for women and men separately, inasmuch as important sex differences exist.

Women with RA are more likely to come from homes which were high on parental status stress, i.e., high discrepancies between the several social status indicators of mother and father, than are women without RA. Moreover, the RA women recall their mother's authority and disciplining as much more arbitrary (unreasonable, severe, irritable, and controlling); their reaction to such arbitrary authority was high covert hostility but very low overt resistance and aggressiveness. In spite of this negative picture of the mothers, the RA women chose them as often for role (identification) models, as did the women without RA. The descriptions of the father's behavior and reactions to him showed no differences between RA's and non-RA's. 
The current personality of the RA women shows a good deal of continuity with their childhood situation. These women appear to be particularly high on conflicts over expression of and control of anger and aggressive impulses: their level of angerirritation is particularly high, but they appear to want to control it and their guilt about expressing anger and aggression is as strong as for women without RA. Worth noting is also the fact that on diverse measures of poor mental health, the RA women consistently report more symptoms.

The marriages of the RA women are particularly interesting. Their marriage is more likely to be characterized by high status stress (high discrepancies between their own and their husband's status variables) and they are more likely to be married to men whose own status variables are incongruent. Thus in this respect, the marriages of the RA women resemble the marriages of their parents. Moreover, the RA women feel and express a good deal of anger and aggression toward their husbands. The husbands seem to reciprocate and these marriages are thus high on mutually directed anger-aggression. Men married to RA women are more likely to have peptic ulcer; furthermore, there is some evidence that the men with the ulcer have strong unmet needs for emotional support, unmet because of the high hostility and resentment of the $\mathrm{R} \Lambda$ wife. An interesting feature of these marriages is that, in spite of this high mutual hostility, they are not different on marital integration, satisfaction, and trust, from marriages where both partners are free of RA and ulcer.

The picture of the men with RA is more uncertain, partly because of the smaller number of cases involved. Men with RA are somewhat less likely to come from homes which were high on parental status stress than are men without RA. Moreover, the RA men recall their mother's authority and discipline as having been less arbitrary; their behavior towards their mothers was characterized by low covert hostility. The descriptions of the father's behavior and reactions to him again showed no differences between the RA's and the non-RA's.

Like the RA women, the RA men report consistently more symptoms on diverse measures of poor mental health than do the healthy respondents. However, on diverse measures of anger and aggressive impulses, the RA men reveal differences from non-RA's in the opposite direction than were the differences between RA and nonRA women: the RA men are low on anger-aggression. Moreover, this difference is most striking in the spouse area and since the wives of the RA men reciprocate with equally low anger-aggression, the marriages of RA men and healthy women are particularly low on marital hostility. For methodological reasons, it is not quite clear whether the male RA is more controlled in the expression of his angry and aggressive feelings, or whether he experiences them less frequently to start with. 